\title{
The Role of COSPAR for Space Security and Planetary Protection
}

\author{
Leslie I. Tennen
}

\section{Contents}

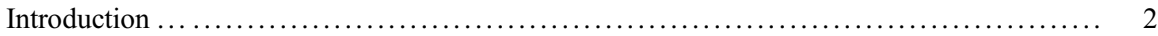

The Committee on Space Research .......................................... 3

Foundations and Development of the Planetary Protection Policy ..................... 4

Initial Activities of the Diplomatic Community ................................. 4

Initial Scientific Policies .................................................. 4



Scientific Regulation Tthrough Planetary Quarantine Requirements ................. 5

Planetary Protection and the Emergence of Binding International Law ................ 7



The Moon Agreement and Elaboration of Legal Regulation ...................... 8

Transformation of the PQR ............................................... 9



Categorization of Target Bodies .......................................... 9

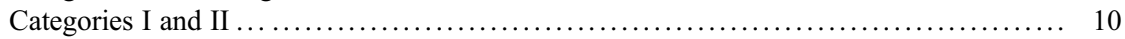

Category III: Flyby and Orbiter Mission to Mars, Europa, and Enceladus ............. 10

Category IV: Lander Missions to Mars, Europa, and Enceladus ................... 11

Category V Sample Return Missions ..................................... 11

Human Missions to Mars .............................................. 13

Implementation of the COSPAR PPP by Space Agencies and Authorities ................ 14

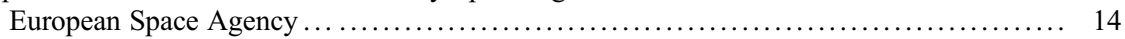

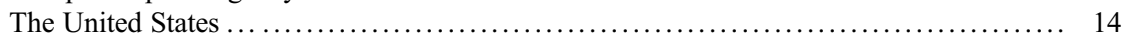

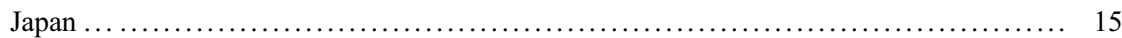



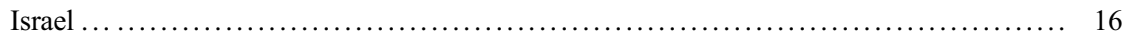

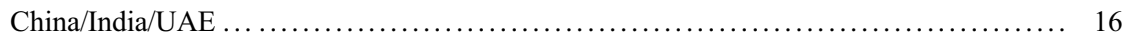

L. I. Tennen (四)

Law Offices of Sterns and Tennen, Glendale, AZ, USA

e-mail: Ltennen@astrolaw.com 


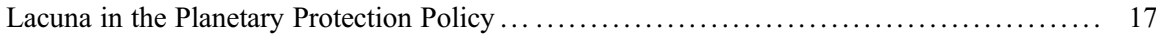

Expand Target Bodies in Categories III and IV ................................ 17

Missions to Phobos and Deimos Can Increase the Risk of Contaminating Mars ......... 18

Challenges to Planetary Protection by Private Sector Commercial Projects ............. 19

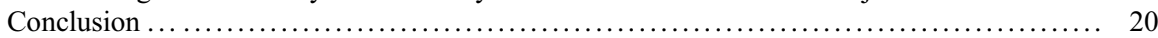



\section{Abstract}

The environment of the Earth can be at risk of potential contamination from extraterrestrial material brought back to this planet by robotic and human explorers. Similarly, spacecraft sent to explore celestial bodies can carry microbes that can contaminate an extraterrestrial environment. Contamination presents significant implications for space security. The Committee on Space Research (COSPAR) of the International Science Council (ISC) has maintained a Planetary Protection Policy (PPP) to address both forward and back contamination. States have implemented the COSPAR PPP as the recognized standard to comply with international treaty obligations in regard to contamination from biological matter.

\section{Introduction}

How did life begin? Are we alone in the universe? These questions are among the most essential, eternal, and enduring mysteries of science. With the advent of the space age, mankind acquired new capabilities to search for alien life. We have the technology to venture to distant worlds, conduct experiments in the pursuit of evidence of life, and even bring samples from celestial bodies back to our home planet. However, extraterrestrial matter brought back to the Earth could potentially harbor deleterious material that could jeopardize the safety and security of the entire globe. This issue of "back contamination" is not confined to the realm of science fiction but has been a significant concern since the days of the Apollo program.

Just as the environment of the Earth is in need of protection from potential harmful contamination from extraterrestrial sources, so it is also necessary to protect celestial environments from harmful contamination from terrestrial matter. The discovery of evidence of life on another celestial body would forever change humanity's view of mankind's place in the cosmos. The significance of such a discovery cannot be overstated, nor can it be completely comprehended in advance; therefore it is of the utmost importance that the scientific integrity of such a discovery be assured. Forward contamination of a celestial environment from terrestrial biological materials could jeopardize the scientific integrity of subsequent investigation and also could harmfully interfere with future exploration and experimentation. This directly impacts the risk of conflict between nations and threatens the safeguarding of space for peaceful endeavors. 
In its most basic terms, forward contamination controls seek to ensure that any evidence of life found on a celestial body is indigenous and not of terrestrial origin. Similarly, back contamination requirements are a way to answer the question of how will we know that extraterrestrial matter brought back to the Earth will not be dangerous. The policy of planetary protection can be summarized as follows:

The conduct of scientific investigations of possible extraterrestrial life forms, precursors, and remnants must not be jeopardized.

The Earth must be protected from the potential hazard posed by extraterrestrial matter carried by a spacecraft returning from a celestial body. (Coustenis et al. 2019)

\section{The Committee on Space Research}

The international diplomatic and scientific communities have acted to prevent both forward and back contamination. The United Nations has been the leading organization for the development of legal principles to protect celestial environments. The Committee on Space Research (COSPAR) has been the preeminent scientific forum for the articulation of specific policies and guidelines for planetary protection (the Planetary Protection Policy or PPP).

COSPAR was formed in 1958 by the International Council of Scientific Unions (ICSU), now the International Science Council (ISC). The membership of COSPAR is comprised of national scientific institutions and international scientific unions. The organizational structure consists of eight commissions which represent every scientific discipline involved in space research. In addition, there are ten panels which are designed to deal with issues of interest to specific segments of the space research community. The prevention of forward and back contamination is the charge of the Panel on Planetary Protection (PP Panel).

The PP Panel is appointed by the COSPAR Bureau and is led by a chair and two vice-chairs, one of which is reserved for a representative of the United Nations Office for Outer Space Affairs (UNOOSA). There is an equal number of representatives from national or international authorities and representatives from COSPAR Scientific Commission B, Space Studies of the Earth-Moon System, Planets, and Small Bodies of the Solar System, and Commission F, Life Sciences as Related to Space.

The competence of the COSPAR PP Panel is limited to forward and back contamination from biological sources. As such, it is primarily concerned with microbes and other potential organic contaminants. The COSPAR PP Panel does not otherwise consider protecting celestial bodies, unique environments, or historical sites. Nor does the COSPAR Planetary Protection Policy apply to protecting the Earth from man-made space debris or defending the planet from the impact of large asteroids or comets. 


\section{Foundations and Development of the Planetary Protection Policy Initial Activities of the Diplomatic Community}

In 1957, the United Nations General Assembly took the first formal steps to regulate mankind's movement into the cosmos by the creation of the Ad Hoc Committee on the Peaceful Uses of Outer Space (COPUOS), which became a permanent committee the following year. COPUOS conducts its work through two subcommittees, one of which is devoted to scientific and technical matters, while the other considers legal issues. Membership in the Committee has expanded over the years to include all states actively launching and performing missions in space. Currently 95 nations are members of COPUOS, and in addition a number of international organizations, including both intergovernmental and nongovernmental entities, have observer status in the Committee. COPUOS and its subcommittees function on the basis of consensus.

\section{Initial Scientific Policies}

The Planetary Protection Policy began as a means of self-regulation by the international scientific community and pre-dated any applicable international law. In 1958, within months of the launch of Sputnik I, the ICSU formed the Ad Hoc Committee on Contamination by Extraterrestrial Exploration (CETEX), which considered celestial bodies to be scientific preserves. CETEX identified four primary objectives:

(i) Freedom of exploration of celestial bodies, subject to limitations such as planetary quarantine requirements.

(ii) Disclosure to COSPAR of information concerning activities and experiments.

(iii) Only experiments which are likely to yield useful scientific data should be conducted.

(iv) Nuclear explosions should not occur near the surface of celestial bodies (Tennen 2003/2004).

\section{Policies of Planetary Protection}

In March 1962, Chairman Khrushchev of the Soviet Union drew the attention of the diplomatic community to the issue of protecting planetary environments. The Chairman wrote a letter to President Kennedy about what he described as "heavenly matters" and proposed that:

in carrying out experiments in outer space, no one should create obstacles to the study and use of space for peaceful purposes by other States. . . any experiments in outer space which may hinder the exploration of space by other countries should be the subject of preliminary discussion and of an agreement... (emphasis added) 
Khrushchev inextricably linked protection of celestial environments to the right of states to conduct activities in the exploration and use of outer space. His focus, however, was not on the intrinsic value of preserving pristine celestial environments. Rather Khrushchev asserted and sought to protect the right of states to conduct activities in space without hindrance created by the activities of other states. $\mathrm{He}$ proposed that there should be a right to prior consent over activities and experiments of other states (Jakhu and Pelton 2017).

These and other issues were subject to debate and discussion in COPUOS, which recognized that the problem of preventing potentially harmful interference in the peaceful uses of outer space was of urgent concern. On November 22, 1963, COPUOS unanimously approved the Declaration of Legal Principles Governing the Activities of States in the Exploration and Use of Outer Space. The General Assembly of the United Nations thereafter adopted the Declaration of Principles as Resolution 1962. Planetary protection concerns were addressed in Paragraph 6:

In the exploration and use of outer space, States shall be guided by the principle of cooperation and mutual assistance and shall conduct all their activities in outer space with $d u e$ regard for the corresponding interests of other States. (emphasis added)

The Declaration further provided that a state which has reason to believe its activities or experiments may cause harmful interference with the activities of another state shall undertake appropriate consultations with such second state. Similarly, if a state believes its activities may be interfered with by the activities of another state, it could request such other state to participate in consultations. This first legal planetary protection standard approved by the community of nations confirmed the complex interplay between preservation of celestial environments from harmful contamination and due regard for the right of states to conduct activities on other worlds without harmful interference.

\section{Scientific Regulation Tthrough Planetary Quarantine Requirements}

Following the work of CETEX, the ICSU established the COSPAR Consultative Group on Potentially Harmful Effects of Space Experiments, which released a comprehensive Planetary Protection Policy in 1964. This policy established "planetary quarantine requirements" (PQR) which adopted a probabilistic approach to protecting pristine celestial environments (COSPAR 1964). That is, the PQR established limitations expressed as a probability that a spacecraft could contaminate a celestial environment. The probability of contamination $(\mathrm{P}(\mathrm{c}))$ by any mission was determined by the formula:

$$
\mathrm{P}(\mathrm{c})=\mathrm{mi}(0) \cdot \mathrm{P}(\mathrm{vt}) \cdot \mathrm{P}(\mathrm{uv}) \cdot \mathrm{P}(\mathrm{a}) \cdot \mathrm{P}(\mathrm{sa}) \cdot \mathrm{P}(\mathrm{r}) \cdot \mathrm{P}(\mathrm{g})
$$


where

mi(O) Initial microbial burden (at launch, after decontamination)

$\mathrm{P}(\mathrm{vt})$ Probability of surviving space vacuum-temperature

$\mathrm{P}(\mathrm{uv})$ Probability of surviving ultraviolet space radiation

$\mathrm{P}(\mathrm{a})$ Probability of arriving at planet

$\mathrm{P}(\mathrm{sa})$ Probability of surviving atmospheric entry

$\mathrm{P}(\mathrm{r})$ Probability of release

$\mathrm{P}(\mathrm{g})$ Probability of growth

The PQR set a probability limit for an accidental planetary impact by an unsterilized flyby or orbiting spacecraft to be $3 \times 10^{-5}$ or less $(<1 / 300,000)$. Spacecraft which were intended to penetrate the atmosphere or land on the surface of a planet were subject to a much higher standard. For these spacecraft, the probability limit for contamination by a single viable terrestrial organism aboard the craft was to be less than $1 \times 10^{-4}(<1 / 10,000)$. These $\mathrm{P}(\mathrm{c})$ limits were to apply for an initial period of planetary exploration of 10 years, later extended to 30 years (Phillips 1975).

In 1966 the $\mathrm{P}(\mathrm{c})$ limit for landing or atmospheric penetration spacecraft was reduced to $1 \times 10^{-3}(1 / 1000)$. This probability limit was an aggregate for all missions from all nations, and individual countries were allocated specific portions of the overall probability limits. The recipient states, in turn, apportioned their share among the various missions each conducted. The overall $\mathrm{P}(\mathrm{c})$ limits were divided as follows (Meltzer 2012):

$\begin{array}{ll}\text { USA } & 4.4 \times 10^{-4} \\ \text { USSR } & 4.4 \times 10^{-4} \\ \text { All others } & 1.2 \times 10^{-4} \\ \text { Total } & 1 \times 10^{-3}\end{array}$

The United States, in turn, distributed its national allotment to the following interplanetary missions (Sterns and Tennen 2019):

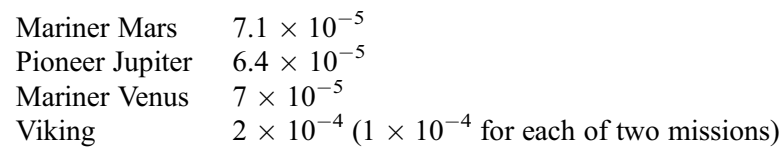

Compliance with the PQR generally required missions to engage in active decontamination techniques to reduce the presence of microbes on the spacecraft at launch. States employ a variety of techniques for this purpose. Prevention and limitation of the initial microbial burden are achieved by assembly and testing of a spacecraft in biologically controlled cleanrooms. The bioburden is reduced by cleaning with various solvents and by dry heat, plasma, or ionizing radiation. Barrier systems such as purging, filters, and seals are utilized to avoid possible re-contamination of the 
spacecraft. However, absolute sterilization of a spacecraft is not considered possible (Meltzer 2012).

\section{Planetary Protection and the Emergence of Binding International Law}

The legal regulation of activities in space entered a new phase when COPUOS reached consensus on the text of the Treaty on Principles Governing the Activities of States in the Exploration and Use of Outer Space, including the Moon and Other Celestial Bodies (OST), which entered into force in October 1967. Article I of the OST recognizes the right of states to conduct peaceful activities on all areas of the Moon and other celestial bodies. Article IX of the treaty incorporated the due regard and consultation provisions of GA Res. 1962, the Declaration of Principles. In addition, and significantly, Article IX went further and explicitly addressed planetary protection and provided that in pursuing studies and conducting exploration of celestial bodies, states shall:

avoid their harmful contamination and also adverse changes to the environment of the Earth resulting from the introduction of extraterrestrial matter and, where necessary, shall adopt appropriate measures for this purpose.

Article IX is very broad in its terms and encompasses not just the concepts of due regard for, and the prevention of, harmful interference with activities of other states but also the inherent value in the preservation of natural celestial environments from harmful contamination. Nevertheless, there is no international consensus on the definitions of "harmful contamination" or "interference." Nor have the interests of other states that shall be given due regard been identified, other than avoidance of harmful contamination. However, the COSPAR PPP represents a consensus that, at a minimum, harmful contamination includes the introduction of biological matter from the Earth into at least certain celestial environments.

\section{Revisions to the PQR}

The COSPAR Planetary Protection Policy has not been static but rather has been subject to continuing review and revision. Within COSPAR is a recognized process by which changes to the policy can be considered, evaluated, and examined by pertinent stakeholders, including scientific commissions of COSPAR and members of the international planetary science community (Coustenis et al. 2019). As part of this process, the probabilistic approach on which the PQR was based was criticized for the inherent difficulty of assigning specific numerical values to criteria with largely unknown properties in order to determine the probability of contamination for a mission. Recognizing this difficulty in application of the PQR, COSPAR in 1969 limited the policy to missions to Mars and other planets deemed important in the search for extraterrestrial life (Stabekis 2002). 
This change in the application of the policy was a significant departure from manner in which the risk of contamination to a celestial environment was viewed. The PQR proceeded from the original perspective articulated by CETEX that celestial bodies were scientific preserves, and as such the PQR were presumed to be applicable to all interplanetary missions. The revisions to the PPP, however, limited the applicability of the decontamination requirements to only a small subset of interplanetary missions.

Subsequent revisions to the policy reinforced this change in perspective. For example, in 1978, the probability that terrestrial organisms could grow in extraterrestrial environments was re-evaluated and deemed to be virtually zero for most celestial bodies (Space Science Board 1978). As a result, requirements that missions to those bodies engage in active decontamination techniques were largely eliminated. The movement away from the probabilistic approach turned protection of celestial environments from a comprehensive blanket policy to one of restricted application. That is, PQR became the exception, not the norm, and active decontamination techniques would not be required for missions to alien worlds deemed too hostile for terrestrial microbes to survive and replicate.

\section{The Moon Agreement and Elaboration of Legal Regulation}

In 1979 COPUOS achieved consensus on a second treaty which addressed forward and back contamination, the Moon Agreement (MA), which provides, in Article 7.1:

In exploring and using the Moon, States Parties shall take measures to prevent the disruption of the existing balance of its environment whether by introducing adverse changes in that environment, by its harmful contamination through the introduction of extra-environmental matter or otherwise. States Parties shall also take measures to avoid harmfully affecting the environment of the Earth through the introduction of extraterrestrial matter or otherwise. (emphasis added)

The obligations of states under the MA are more extensive than required by the OST. While the MA prohibits harmful contamination, as does the OST, the MA also prohibits states from disrupting the existing balance of the lunar environment. (Pursuant to Article 1.1 the provisions of the MA apply to other celestial bodies in the Solar System unless specific legal norms enter into force for such objects.) The MA makes it clear that environmental disruption could occur by several means, including but not limited to harmful contamination by the introduction of extraenvironmental biological and other matter.

Article 7 contains a further departure from the OST in paragraph 3, which provides that states shall notify the Secretary General of areas of the Moon with special scientific interest, so that consideration shall be given to the designation of an area as an "international scientific preserve." Such areas shall be subject to "special protective arrangements to be agreed upon in consultation with the competent bodies of the United Nations." 
The Preamble to the MA reflects that the treaty was formulated, in part, to define and develop the provisions of the OST, thereby providing some clarification as to the meaning of Article IX. However, the MA has not received widespread acceptance by the community of nations. While the OST has been signed or ratified by more than 130 states, only 18 states have ratified the MA, and just 4 more have signed the instrument. These include India and members of ESA including Belgium, France, the Netherlands, and Austria. These states must ensure that any mission to celestial bodies in which they participate is conducted in compliance with their international obligations, including the MA (Jakhu and Pelton 2017).

\section{Transformation of the PQR}

The derogation of the PQR continued into the 1980s, when the requirements were replaced with a new approach that provided the imposition of planetary protection constraints would be dependent upon the nature of the mission and the target body or bodies to be explored. These guidelines completely eliminated the overall probability of contamination restrictions and did not require any decontamination techniques or documentation for target bodies which were deemed not to be of biological interest in the search for life, including the Moon. The planetary protection classification for missions to other target bodies was to be determined on a case-by-case basis (Stabekis 2002).

Subsequent revisions continued to erode and limit the application of the PPP. In addition to the prerequisite conditions that a target body be both biologically interesting and deemed to provide an environment in which terrestrial microbes could survive and replicate, a third condition was added: that the mission spacecraft must include experiments intended to detect evidence of extraterrestrial life. An exception to this condition has been carved out for missions to areas of a celestial body which are designated as a "special region," that is, an area which possesses properties which are known to be conducive to sustaining life in terms of temperature range and the presence of water. Spacecraft intended to land or explore or create (even temporarily by the operation of spacecraft hardware) a special region must achieve Viking-level decontamination, even where the mission does not include life detection experiments. However, the designation of an area as a special region under the PPP is not to be considered as the equivalent to an international scientific preserve pursuant to Article 7.3 of the MA. Special regions are expressly defined in relation to the search for evidence of indigenous life, while the designation as a scientific preserve is not limited to this purpose.

\section{Current COSPAR Planetary Protection Policy}

\section{Categorization of Target Bodies}

The overarching policy is stated by COSPAR as follows (COSPAR 2017): 
The conduct of scientific investigations of possible extraterrestrial life forms, precursors, and remnants must not be jeopardized. In addition, the Earth must be protected from the potential hazard posed by extraterrestrial matter carried by a spacecraft returning from an interplanetary mission. Therefore, for certain space mission/target planet combinations, controls on contamination shall be imposed in accordance with issuances implementing this policy

The implementation of the policy divides celestial bodies and mission types into four categories, with a fifth category designated for the return of extraterrestrial materials to the Earth. The concern for contamination and the concomitant contamination controls vary by category.

\section{Categories I and II}

Category I consists of flyby, orbiter, and landing missions to target bodies which are not considered to be of significant interest in the search for life, such as Io and undifferentiated, metamorphosed asteroids. No specific PPP requirements are imposed for such mission/target body combinations.

Category II consists of flyby, orbiter, and landing missions to most of the moons in the solar system, including the Moon of the Earth, the planets - including Pluto other than Mars, carbonaceous chondrite asteroids, comets, and some Kuiper belt objects. These target bodies are considered to be of "significant interest relative to the process of chemical evolution and the origin of life, but where there is only a remote chance that contamination carried by a spacecraft could compromise future investigations." The term "remote" in this context "implies the absence of environments where terrestrial organisms could survive and replicate.. . (emphasis added)." Category II missions are subject to only simple documentation requirements, consisting of "a short planetary protection plan" identifying possible impact sites, brief pre- and post-launch analyses of impact strategies, and a post-encounter or mission report providing the location of any impact which occurred.

\section{Category III: Flyby and Orbiter Mission to Mars, Europa, and Enceladus}

Category III target bodies are of both significant interest in the search for evidence of life and carry a significant chance that contamination could compromise future investigations. Since these missions are not intended to impact the target body, the policy allows for the spacecraft to satisfy a requirement of either orbital lifetime parameters or bioburden reduction. Orbital lifetime parameters require a probability of greater than or equal to $99 \%$ that the spacecraft will not impact the target body within 20 years of launch and greater than or equal to $95 \%$ on non-impact within 50 years. The bioburden reduction requirements limit the total number of spores on and in the spacecraft to less than or equal to $5 \times 10^{5}$ (Spores are defined as aerobic 
microorganisms that survive a heat shock of $80{ }^{\circ} \mathrm{C}$ for $15 \mathrm{~min}$ and cultured on Tryptic-Soy-Agar at $32{ }^{\circ} \mathrm{C}$ for $72 \mathrm{~h}$ ).

\section{Category IV: Lander Missions to Mars, Europa, and Enceladus}

Category IV for landing craft is divided into three subcategories, depending on the mission type and objectives. Subcategory IV(a) applies to spacecraft which do not carry instruments designed to search for extant life. These spacecraft must meet bioburden limits of a total of less than or equal to $3 \times 10^{5}$ spores and an average of not more than 300 spores per square meter.

Category IV(b) missions are designed to search for extant extraterrestrial life. Such missions are required to meet bioburden reduction levels four orders of magnitude more stringent than for Category IV(a) spacecraft, that is, a total of 30 spores, or the "levels of bioburden reduction driven by the nature and sensitivity of the particular life detection experiments." However, if the life detection experiment hardware is cleaned to this level and the spacecraft is designed to ensure that the hardware cannot be exposed to possible recontamination, the remainder of the spacecraft can satisfy the PPP by meeting Category IV(a) limits.

Category $\operatorname{IV}(\mathrm{c})$ is for missions to special regions. Spacecraft landing within a special region must comply with Category IV(b) limits. If the special region is accessed through horizontal or vertical mobility, either the entire spacecraft or the subsystems which will encounter the special region must reach that level of cleanliness, and in the event of the latter, the subsystems must be designed to prevent recontamination after the bioburden is reduced.

\section{Category V Sample Return Missions}

The four mission type/target body categories described above are concerned with forward contamination. The issue of back contamination is addressed in Category V, which applies to sample return missions. These sample return missions are classified as either restricted or nonrestricted. Missions to the Moon or Venus are nonrestricted Earth return and do not require any specific decontamination measures to be utilized. However, missions returning samples from Mars or Europa are restricted Earth return and warrant the highest level of caution to protect the Earth from potentially catastrophic contamination. (The importance of protective measures from potential back contamination is undeniably demonstrated by the Covid-19 health crisis which is devastating the globe as this chapter is in preparation.)

The PPP requires that the outbound leg of a restricted Earth return mission follow Category IV(b) requirements, to guard against "false positives" in experiments searching for extraterrestrial life. Unless the samples are to be sterilized prior to return to the Earth, the samples are to be kept in closed containers and a means provided to "break the chain of contact" with the target body. The PPP further provides that mission reviews and approvals are to be conducted at three stages: prior 
to launch from the Earth, after sample collection and before maneuvers to enter a biased Earth return trajectory, and prior to commitment to Earth reentry. In addition, unsterilized samples are either to be sterilized or subject to a program of life detection and biohazard testing, as an absolute precondition to the controlled distribution of any portion of the sample.

In 2019, in response to a request from JAXA for guidance, the COSPAR PP Panel recommended that sample return missions to Phobos and Deimos be designated as nonrestricted Earth return (Coustenis et al. 2019). Samples to be returned from other small bodies in the solar system, which are not otherwise categorized, are to be designated as restricted or nonrestricted on a case-by-case basis. The criteria for this determination are set out in the PPP, as a series of questions:

1. Does the preponderance of scientific evidence indicate that there was never liquid water in or on the target body?

2. Does the preponderance of scientific evidence indicate that metabolically useful energy sources were never present?

3. Does the preponderance of scientific evidence indicate that there was never sufficient organic matter (or $\mathrm{CO} 2$ or carbonates and an appropriate source of reducing equivalents) in or on the target body to support life?

4. Does the preponderance of scientific evidence indicate that subsequent to the disappearance of liquid water, the target body has been subjected to extreme temperatures (i.e., $>160{ }^{\circ} \mathrm{C}$ )?

5. Does the preponderance of scientific evidence indicate that there is or was sufficient radiation for biological sterilization of terrestrial life forms?

6. Does the preponderance of scientific evidence indicate that there has been a natural influx to the Earth, e.g., via meteorites, of material equivalent to a sample returned from the target body?

For containment procedures to be necessary ("restricted Earth return"), an answer of "no" or "uncertain" needs to be returned to all six questions.

The sample return missions which have been launched since Apollo have all been nonrestricted, as these missions to comets, asteroids, or Phobos were not intended to return samples from a body deemed capable of supporting life. This situation will soon change as NASA is preparing to launch the first restricted Earth return mission, Mars 2020. This mission is planned to land on the red planet in 2021 and includes the capability to collect 40 separate samples of Martian material for return to the Earth. Mars 2020 is not itself a sample return mission but only a precursor to an as of yet not fully defined future mission that will return the collected samples. Nevertheless, these samples are subject to the standards of restricted Earth return, and the protocols to be developed for containing, isolating, transporting, and investigating any such samples are not without current controversy (MSR Science Planning Group Report 2019). 


\section{Human Missions to Mars}

Robotic sample return missions such as Mars 2020 are a stepping stone to the eventual human exploration of the planet. Application of the COSPAR PPP is not limited to robotic missions, although the introduction of crews into the equation considerably complicates matters. The PPP recognizes that it will not be possible for human explorers to operate in entirely closed systems, nor can exposure with Martian materials be avoided. Moreover, the limitations on the initial microbial burden transported by robotic spacecraft are inapposite and unsuitable for human missions, which "will carry microbial populations that will vary in both kind and quantity. .." Accordingly, the PPP identifies specific implementation guidelines for human missions to Mars, including:

The development of a comprehensive protocol for addressing forward and backward contamination concerns during all phases of a mission.

Continuous monitoring and evaluation of microbes carried by a mission.

The designation of a member of the crew with primary responsibility for implementing planetary protection provisions.

A quarantine capability for the crew during and after the mission in case of potential contact with a Martian life form.

Robotic precursors to evaluate whether or not a site should be characterized as a special region prior to crew access.

Planetary protection requirements for human missions should be based on a conservative approach recognizing the lack of specific knowledge of the Martian environment, possible life, and the utility and efficacy of human support systems.

Planetary protection requirements for subsequent missions should not be relaxed without scientific justification and consensus.

The development of the necessary policies and procedures will be able to draw upon the experience and precedent of the Apollo program, in particular in regard to the Lunar Receiving Laboratory. The astronauts of Apollo 11, 12, and 14 were subject to quarantine upon their return from the Moon, as were the lunar materials they brought back to the Earth, until it was determined that they had not been exposed to harmful extraterrestrial contamination. It is known that the microbe Microbispora survived the harsh conditions of the ill-fated reentry of Columbia, (McLeana et al. 2006), and the possibility exists that terrestrial organisms can mutate in space and present new dangers. The lessons of Apollo can be instructive from technical, operational, and management perspectives, as issues were encountered in each area that resulted in certain breaks in the biological barrier that must not be repeated with Martian materials (Mangus and Larsen 2004). 


\section{Implementation of the COSPAR PPP by Space Agencies and Authorities}

The COSPAR PPP requirements do not have the force of binding law as they are neither a treaty nor a formal intergovernmental agreement. The specific requirements set forth in the PPP are more in the nature of guidelines rather than compulsory obligations, and COSPAR does not direct the manner in which competent national authorities and international agencies can implement the policy. States which launch or register a spacecraft are internationally responsible and liable for the mission pursuant to the OST and have the duty to comply with Article IX to prevent the harmful contamination of celestial environments. COPUOS has recognized the PPP as the international reference standard for guiding compliance with Article IX of the OST in relation to contamination from biological sources (COPUOS 2017), but the PPP is not necessarily the only method by which states can comply with the treaty. Nevertheless, space active states generally have sought to satisfy the specific requirements articulated by COSPAR, and several agencies have incorporated the substantive provisions of the PPP into their formal governing documentation.

\section{European Space Agency}

The Council of the European Space Agency (ESA) has adopted the "ESA Planetary Protection Policy." The ESA PPP is implemented by specific "ESA Planetary Protection Requirements," which are based on and consistent with the COSPAR PPP, and set forth the Agency's overall planetary protection management responsibilities. These include technical requirements for robotic and human missions, requirements related to procedures, and descriptions of necessary documentation (Kminek 2017). In addition, this document contains internal ESA organizational descriptions and requirements. Neither the ESA PPP nor the ESA PPR have been released to the public. However, specific standards have been published by the European Cooperation for Space Standardization (ECSS) in "Space Sustainability - Planetary Protection" which are to be followed by ESA member states in their own projects. The ESA PPP and corresponding implementation standards apply to spaceflight missions conducted by ESA and to contributions to ESA spaceflight missions. Significantly, the ESA PPP also applies to ESA contributions to non-ESA spaceflight missions, such as missions conducted by other states, agencies, or the private sector which are launched by ESA or from ESA facilities.

\section{The United States}

NASA has adopted NASA Policy Directive NPD 8020.7G, "Biological Contamination Control for Outbound and Inbound Planetary Spacecraft," which mirrors the COSPAR policy statement. 
The NPD is implemented by NASA Procedural Requirements NPR 8020.12D, "Planetary Protection Provisions for Robotic Extraterrestrial Missions," which are based on and are in conformity with the COSPAR PPP. Pursuant to the NASA policy, the agency has established a Planetary Protection Officer, with responsibility to categorize missions and oversee compliance with the Planetary Protection Policy.

In 2017, NASA promulgated NASA Interim Directive NID 8020.109A, "Planetary Protection Provisions for Robotic Extraterrestrial Missions." Section 2.2 of this NID concerns NASA participation in non-NASA or non-US Missions, which assigns sole responsibility for planetary protection categorization and certification of compliance to the lead and launching organizations. Subsection 2.2.2 provides:

NASA shall provide hardware, services, data, funding, and other resources to non-NASA missions (including but not limited to resources agreements) only if the recipient organization(s), whether governmental or private entity, demonstrate adherence to appropriate policies, regulations, and laws regarding planetary protection that are generally consistent with the COSPAR Planetary Protection Policy and Guidelines

\section{Japan}

Japan has launched several deep space explorations, including the Hayabusa 2 asteroid sample return mission currently in progress, without an overarching Planetary Protection Policy document in place. Nevertheless, individual projects implemented the COSPAR PPP by the adoption of conforming design standards and by achieving agreement with the COSPAR Planetary Protection Panel. Japan steadily has been increasing its space exploration activities, and in December 2018 JAXA established a planetary protection organization. Shortly thereafter, the agency issued a formal Planetary Protection Policy and associated requirements which are compliant with the COSPAR PPP, JAXA Management Requirement JMR-014, "Planetary Protection Program Standards." These standards specify administrative, technical, and procedural aspects of planetary protection for both forward and back contamination. These standards apply to missions conducted by JAXA, parties who participate in missions conducted by JAXA, and JAXA's participation in missions hosted by other organizations.

\section{Russia}

The Russian Federal Law "On space activities" Decree No. 5663-1, Article 6, designates the State Corporation Roscosmos as the body authorized to ensure the safety of space activities. Article 4.1 provides that Roscosmos is responsible for ensuring that space activities are carried out in accordance with the principle of environmental protection. In order to ensure "strategic and ecological security," Article 4.2 prohibits the creation of "harmful contamination of outer space which 
leads to unfavorable changes of the environment, ..." This prohibition appears to be more limited than is Article IX of the OST, which expressly includes "the Moon and other celestial bodies" as part of outer space. The omission of specific reference to the Moon and other celestial bodies in this subsection of the Russian law indicates that it is directed only to the outer space environment, as another subsection expressly prohibits the use of the Moon and other celestial bodies for military purposes. In addition, the express direction that harmful contamination includes the deliberate elimination or destruction of space objects in outer space implies objects in Earth orbit. Nevertheless, Article 26.3 affirms the duty of Russia to fulfill its obligations under the OST.

Russian Federal Laws "on technical regulation" No. 184-FZ, and "on sanitary and epidemiological well-being of the population" No. 52-FZ, address safety in general, including biological safety, but do not contain specific rules dedicated or directly addressed to issues of forward or back contamination. Nor apparently has Roscosmos publicly issued any official documents related to policies, procedures, or standards related to the biological protection of the Earth from the risks associated with space missions (Dobrokhotsky et al. 2012). However, missions such as PhobosGrunt sample return were reviewed and approved as being in compliance with the COSPAR PPP, although the reliability of such certification can be questioned (Sterns and Tennen 2019).

\section{Israel}

Israel has conducted a lunar mission and is planning future missions but does not have a publicly available formal Planetary Protection Policy governing document. The Israel IL lunar landing craft Beresheet was launched on a private American rocket from a NASA launch facility in Florida. As such, per NASA NID 8020.109A, the craft was subject to the NASA policy and requirements as set forth in NPD $8020.7 \mathrm{G}$ and NPR 8020.12D. Beresheet crashed on the lunar surface while attempting to land. Several months later reports began to circulate that a payload supplied by a third party had secretly encased some tardigrades, a primitive form of life, into some components that were carried to the Moon. A deliberate failure to disclose the presence of living organisms on a spacecraft launched to a celestial body would violate US law and policy (Johnson et al. 2019).

\section{China/India/UAE}

China, India, and the UAE are each conducting missions to celestial bodies but do not have publicly available formal Planetary Protection Policy governing documents. The Chinese have a long history of space exploration, and have participated in COSPAR since 1993. China has sent four spacecraft to the Moon, the most recent of which is the Chang'e-4 that soft landed on the lunar far side in January, 2019, and continues to operate together with the Yutu-2 rover. China also sent a Martian 
orbiter, Yinghuo-1, and a microgravity grinding tool as payloads on the PhobosGrunt mission. The Chinese plan to launch an orbiter and rover, Tianwen 1, to Mars in July 2020. Although an internal coordination mechanism has been implemented to formulate a relevant work plan for this mission, the Chinese are deferring formalizing a planetary protection policy pending further practice and research work.

The Indian Space Research Organization launched the Mars Orbiter Mission and the Chandrayaan mission to the Moon, and the agency followed the COSPAR policy for both missions. ISRO currently is planning additional lunar and planetary missions and is in the process of preparing a formal Planetary Protection Policy. The UAE is preparing for the launch of the "Hope Probe" to Mars. The Emirates have embarked upon an ambitious program to become a significant participant in space activities. The UAE Space Agency is in the process of developing internal policies and procedures, including legal regulation; however it has not been publicly announced whether these policies, procedure, and regulations will include planetary protection considerations.

\section{Lacuna in the Planetary Protection Policy}

The COSPAR PPP began as a comprehensive policy that recognized pristine celestial environments to be scientific preserves and established a Planetary Quarantine Policy applicable to all solar system bodies within our technological reach. Revisions to the policy have narrowed the scope and excluded celestial objects based on scientific explorations and results, new perspectives and approaches to planetary protection, and conclusions drawn regarding the biological interest of particular alien environments vis-a-vis the impact of the introduction of terrestrial organic matter and the ability vel non of terrestrial microbes to survive and replicate in such environments. As the COSPAR PP Panel reviews and re-evaluates the policy, consideration should be given to filling the gaps that remain, including the following:

\section{Expand Target Bodies in Categories III and IV}

The more recent revisions to the PPP have included Europa and Enceladus in the list of target bodies subject to heightened protective measures. Six additional potential ocean worlds have been identified which may support alien life: Titan, Ganymede, Triton, Dione, Callisto, and Pluto. In addition to Mars, recent reports have indicated that Venus also may have been a habitable planet for much of the history of the solar system, and life may be present today in her clouds (Wall 2018; NASA 2016). Even Mercury, which long was considered to be completely uninhabitable, has been discovered to have ice deposits in shielded craters just like the Moon (NASA 2012). These discoveries expand the universe of extraterrestrial environments which are of potential interest in understanding the process of chemical evolution or the origin of life in the solar system, yet few of these target bodies currently are 
categorized so as to require active protective measures. Nevertheless, each category of the PPP notes that additional bodies can be added to any category on a case-bycase basis.

Discoveries of extremophiles on this planet confirm that we must be prepared to encounter life as we do not know it or may not even be able to recognize. Indeed, it was only just over 40 years ago that cellular organisms were discovered to be composed of three distinct types of organisms - archaea, bacteria, and eukarya (Woese and Fox 1977). The gaps in our knowledge are great, and assumptions must be continuously tested. We do know that the basic building blocks of life are not unique to this planet and that once life takes hold, it grabs on tenaciously. It is not possible to conclude that life, or its precursors, could not have been or is not present in environments previously considered inhospitable if not antithetical to life without first conducting specific and thorough scientific investigations.

\section{Missions to Phobos and Deimos Can Increase the Risk of Contaminating Mars}

The categorization of target bodies in the COSPAR PPP has a consequence which may have been unintended but nevertheless places certain celestial objects at increased and unnecessary risk of contamination. Specifically, a focus on a target body fails to adequately consider other bodies that may be within its relative vicinity. This gap within the PPP is illustrated by the Phobos-Grunt mission, which was conducted by the Russian Space Agency in 2011. The mission was intended to land a spacecraft on Phobos, which orbits less than $6000 \mathrm{~km}$ above the surface of Mars, collect samples of surface dirt and rocks, and return them to the Earth. The landing craft included a "bioshield module" provided by the Planetary Society, an American public advocacy organization. Called the "Living Interplanetary Flight Experiment (LIFE)" Project, the bioshield held 11 types of organisms from all three domains of life. These organisms ranged from the "mundane" to the "bizarre" and included extremophiles that were resistant to radiation, desiccation, salt, and heat. The Life Project sought to test the transpermia hypothesis, that is, whether a living organism could survive inside a meteorite and travel from planet to planet.

Phobos is considered to have an environment with a remote chance that terrestrial organisms could survive or replicate and therefore did not require stringent decontamination according to the COSPAR PPP. However, the Life Project BioShield enclosure was specifically designed to enhance and promote the survivability and replication of the organisms housed therein, negating the rationale which underlies Category II classifications.

There is no question but that the intentional introduction of potentially contaminating organisms within $6,000 \mathrm{~km}$ of Mars placed the planet at increased and unnecessary risk of despoiling the environment. Missions to Mars are difficult at best, and sample return missions are inherently more complex and challenging than a flyby, orbiting, or landing mission. The possibilities for a spacecraft off-nominal occurrence on or near Phobos are numerous, especially while engaging in arrival, 
landing, and return maneuvers, any one of which could result in an unintended and uncontrolled encounter with the Martian environment. Such accidental encounters could occur anywhere on the planet, including in special regions.

The launch of the LIFE Project failed to adequately consider the risk to the Martian environment and neither represented the best practice of states nor established good precedent. The mission ended when the spacecraft failed to leave Earth orbit and fell back into the atmosphere and burned up. As a matter of due regard, the PPP should strictly scrutinize any proposed experiment that increases the risk of harmful contamination to a celestial environment, even if it is not the intended target body. Justification for such a mission must demand that the scientific results sought to be attained are of a very high significance and are not available by any other alternative means (Sterns and Tennen 2019).

\section{Challenges to Planetary Protection by Private Sector Commercial Projects}

Additional gaps in the COSPAR PPP are presented by the emergence of New Space commercial ventures. The OST provides in Article VI that states are internationally responsible for the activities of their nationals in space and that nongovernmental entities must be authorized and continuously supervised by their appropriate state. Neither ESA, NASA, nor JAXA authorize private sector activities, and as noted above, the agencies have adopted policies which require adherence with their planetary protection policies for any missions in which they participate. This includes commercial missions; however private sector activities without ESA, NASA, or JAXA participation are not subject to those agencies' internal policy requirement documents. Several states have adopted or are in the process of drafting national licensing regimes for the authorization and supervision of New Space activities (Jakhu and Pelton 2017). However, to date none of these national regimes has included specific reference to, or a requirement to comply with, the COSPAR PPP or similar strictures (Babb et al. 2018).

The COSPAR PPP does not address the implications and ramifications of the discovery of evidence of alien life. The scientific community presumably would take all necessary steps to protect and preserve the evidence and proceed with additional experimentation and exploration with the utmost care. The motivations of the private sector, however, are not necessarily congruent with scientific investigation. Therefore, it is imperative that the Planetary Protection Policy considers the adoption of rules and procedures for the private sector to follow in the event of discovery of evidence of alien life, or the remnants or precursors thereof, or other discoveries of scientific interest.

Policies will need to be developed regarding the disclosure of a discovery of evidence of extraterrestrial life. This would be consistent with the provisions of Article 5.3 of the MA which obligates states to disclose the discovery of any indication of organic life. This disclosure is to be made to the Secretary General, the international scientific community, and the public at large. Private sector ventures 
may be hesitant to make such a disclosure, especially if there is the possibility of obtaining a financial opportunity from intellectual property rights derived from a non-terrestrial microbe (Long 2016).

The area in proximity to a discovery of extraterrestrial life, and other discoveries of scientific interest, must also be protected and preserved. In addition, it must be determined whether commercial activities should be prohibited from conducting resource extraction and other activities from areas of special scientific interest, such as special regions on Mars, pending further scientific investigation (Sterns and Tennen 2019).

Commercial activities present additional issues from a planetary protection perspective, such as the need for the scientific community to be informed of and have the opportunity to express any concerns about proposed missions prior to the issuance of licenses or other authorizations. Private sector missions should be required to disclose an inventory of hazardous materials carried on a spacecraft and provide pre- and post-mission environmental impact assessments for activities conducted in situ.

The focus of the COSPAR PPP on biological contamination is only one aspect of the impact New Space ventures will have on celestial environments. The regulation of the private sector in space will need to consider planetary environmental protection more broadly, such as what requirements, if any, should be imposed on commercial ventures to restore the surface and subsurface of celestial bodies and remove private spacecraft and other objects at the end of their operations. Moreover, historic sites and other unique locations of special interest should be protected from being despoiled in the name of profit.

Whether or not an area has particular historical or scientific interest, appropriate regulation of the private sector will need to consider limitations and prohibitions on materials that can be transported on board a spacecraft and deposited on a celestial object. Commercial ventures have already begun to market the "service" of lunar "burial" of human remains and to carry almost unlimited personal objects on board a landing craft to establish a permanent monument on the Moon. In addition to the obvious environmental impact, erecting shrines to vanity and littering the lunar surface with useless detritus violate any number of provisions of international law, including the non-appropriation principle in Article II of the OST. These commercial ventures harken back to the concerns expressed by Khrushchev in 1962 about activities that create obstacles and hinder the activities of others. The creation of obstacles and hindrances is inherently provocative and destabilizing to space security.

\section{Conclusion}

The protection of celestial environments presents scientific, legal, ethical, moral, aesthetic, and philosophical considerations (Rummel et al. 2012). COSPAR has been the leading scientific organization to articulate and develop a policy of planetary protection, which has been recognized as the international standard for compliance 
with Article IX of the OST regarding protecting against forward and back contamination from biological sources. The COSPAR PPP promotes space security by furthering the interests of science and enhancing the essential goal of international space law to safeguard space, including the Moon and other celestial bodies, for peaceful exploration and use by all states.

\section{References}

Babb RJ, Erb H, Howard D (2018) Cost reduction solutions in regard to PP for commercial companies, IAF Paper No. IAC-18-F1.2.3

COSPAR Planetary Protection Policy, Space Research Today, No. 200, p. 12 (2017). https:// cosparhq.cnes.fr/assets/uploads/2019/12/PPPolicyDecember-2017.pdf. Last accessed February 292020

Coustenis A, Kminek G, Hedman N, Ammannito E, Deshevaya E, Doran PT, Grasset O, Hayes A, Lei L, Nakamura A, Prieto-Ballesteros O, Raulin F, Rettberg P, Sreekumar P, Tsuneta S, Viso M, Zaitsev M, Zorzano-Mier P (2019) The COSPAR panel on planetary protection role, structure and activities, https://cosparhq.cnes.fr/assets/uploads/2019/07/PPP_SRT-Article_Role-Struc ture_Aug-2019.pdf. Last accessed February 292020

Dobrokhotsky ON, Dyatlov IA, Orlov OI, Novikova ND, Hamidullina NM, Deshevaya EA (2012) Ensuring biosafety in the study of samples of extraterrestrial origin by an example of preparation for the "Phobos-Grunt" Mission. https://cyberleninka.ru/article/n/obespechenie-biologicheskoybezopasnosti-pri-issledovanii-materialov-vnezemnogo-proishozhdeniya-na-primere-podgotovkiekspeditsii/viewer (in Russian). Last accessed February 292020

Hofmann M, Retberg P, Williamson M (eds) (2010) Protecting the environment of celestial bodies: the need for policy and guidelines jaxa jmr-014, the planetary protection standards. http://sma. jaxa.jp/TechDoc/Docs/JAXA-JMR-014.pdf (in Japanese). Last accessed February 292020

Jakhu RS, Pelton JN (eds) (2017) Global space governance: an International study 389, 392, 453-54

Johnson CD, Porras D, Hearsay CM and O'Sullivan S (2019) The curious case of the transgressing tardigrades (part 2). https://www.thespacereview.com/article/3786/1. Last accessed February 29 2020

Kminek G (2017) Planetary Protection at ESA. http://pposs.org/wp-content/uploads/2017/03/7.PPOSS-PP-at-ESA-G.-Kminek.pdf. Last accessed February 292020

Long GA (2016) The meaning of life and close encounters of the commercial kind, 2015 proceedings of the international institute of space law 175

Mangus S, Larsen W (2004) Lunar receiving laboratory project history https://www.lpi.usra.edu/ lunar/documents/lunarReceivingLabCr2004_208938.pdf. Last accessed February 292020

McLeana RJC, Welsha AK, Casasanto VA (2006) Microbial survival in space shuttle crash. Icarus 181(1):323-325

Meltzer M (2012) When biospheres collide: a history of nasa's planetary protection programs 82 http://www.nasa.gov/connect/ebooks/when_biospheres_collide_detail.html. Last accessed February 292020

MSR Science Planning Group (2019) Science-driven contamination control issues associated with the receiving and initial processing of the msr samples. https://mepag.jpl.nasa.gov/reports.cfm. Last accessed February 292020

NASA (2012) Messenger finds new evidence for water ice at mercury's poles https://www.nasa. gov/mission_pages/messenger/media/PressConf20121129.html. Last accessed February 29 2020

NASA (2016) NASA climate modeling suggests venus may have been habitable. https://www.nasa. gov/feature/goddard/2016/nasa-climate-modeling-suggests-venus-may-have-been-habitable. Last accessed February 292020 
Phillips CR (1975) The planetary quarantine program: origins and achievements 37 . https://ntrs. nasa.gov/archive/nasa/casi.ntrs.nasa.gov/19750006598.pdf. Last accessed February 292020

Rummel JD, Race MS, Horneck G (2012) Ethical considerations for planetary protection in space exploration: a workshop. Astrobiology 12(11):1017-1023

Space Science Board Committee on Planetary Biology and Chemical Evolution (1978) Recommendations on Quarantine Policy for Mars, Jupiter, Saturn, Uranus, Neptune and Titan 27-28 (Appendix C)

Stabekis P (2002) History and processing of changes, in report, COSPAR/IAU Workshop on planetary protection (Appendix C)

Sterns PM, Tennen LI (2019) Lacuna in the updated planetary protection policy and international law, 23 life sciences in space research $10 \mathrm{https} / /$ www.sciencedirect.com/science/article/pii/ S2214552418301007. Last accessed February 292020

Tennen LI, Evolution of the planetary protection policy: conflict of science and jurisprudence? Proceedings of the 45th colloquium on the law of outer space 466 (2003) and Advances in Space Research 34 (2004): 2354-2362

Wall M (2018) Life on venus? Why its not an absurd thought. https://www.space.com/40304venus-clouds-alien-life-search.html. Last accessed February 292020

Woese CR, Fox GE (1977) Phylogenetic structure of the prokaryotic domain: the primary kingdoms. Proc Natl Acad Sci U S A 74:5088-5090. https://www.ncbi.nlm.nih.gov/pubmed/ 270744. Last accessed February 292020

\section{Additional Reading}

Compendium on mechanisms adopted in relation to non-legally binding United Nations instruments on outer space, Submission by Japan, UN Doc. A/AC.105/C.2/2019/CRP.16 (2 April 2019). http:// www.unoosa.org/res/oosadoc/data/documents/2019/aac_105c_22019crp/aac_105c_22019crp_16_ 0_html/AC105_C2_2019_CRP16E.pdf. Last accessed February 292020

European Cooperation for Space Standardization (ECSS) (1 August 2019) Space Sustainability Planetary Protection, ECSS-U-ST-20C. https://ecss.nl/standard/ecss-u-st-20c-space-sustainabil ity-planetary-protection. Last accessed February 292020

Hofmann M, Retberg P, Williamson M (eds) (2010) Protecting the environment of celestial bodies: the need for policy and guidelines jaxa jmr-014, the planetary protection standards. http://sma. jaxa.jp/TechDoc/Docs/JAXA-JMR-014.pdf (in Japanese). Last accessed February 292020

NASA Interim Directive NID 8020.109A, Planetary Protection Provisions for Robotic Extraterrestrial Missions. https://nodis3.gsfc.nasa.gov/OPD_docs/NID_8020_109A.pdf. Last accessed February 292020

NASA Policy Directive NPD 8020.7G, Biological Contamination Control for Outbound and Inbound Planetary Spacecraft. https://nodis3.gsfc.nasa.gov/displayDir.cfm?t=NPD\&c=8020\&s=7G. Last accessed February 292020

NASA Procedural Requirements NPR 8020.12D, planetary Protection Provisions For Robotic Extraterrestrial Missions, https://nodis3.gsfc.nasa.gov/displayDir.cfm?t=NPR\&c=8020\&s=12D. Last accessed February 292020

Russian Federal Law “On space activities” Decree No. 5663-1 http://www.unoosa.org/oosa/en/ ourwork/spacelaw/nationalspacelaw/russian_federation/decree_5663-1_E.html. Last accessed February 292020 